\title{
Synthesis of Luminescent Ag Nanoclusters with Antibacterial Activity
}

\author{
Ying-Fan Liu, ${ }^{1,2}$ Lei Wang, ${ }^{1}$ Chun-Po Bu, ${ }^{3}$ Guo-Qing Wang, ${ }^{1}$ Yan-Hui Zhang, \\ Shao-Ming Fang, ${ }^{1,2}$ and Wan-Zhen $\mathrm{Shi}^{3}$ \\ ${ }^{1}$ Henan Provincial Key Laboratory of Surface and Interface Science, Zhengzhou University of Light Industry, No. 166, \\ Science Avenue, Zhengzhou 450001, China \\ ${ }^{2}$ Henan Collaborative Innovation Center of Environmental Pollution Control and Ecological Restoration, \\ Zhengzhou University of Light Industry, No. 166, Science Avenue, Zhengzhou 450001, China \\ ${ }^{3}$ College of Chemical and Environmental Engineering, Shandong University of Science and Technology, Qingdao, \\ Shandong 266510, China \\ Correspondence should be addressed to Ying-Fan Liu; yfliu@zzuli.edu.cn and Shao-Ming Fang; mingfang@zzuli.edu.cn
}

Received 5 August 2014; Accepted 14 October 2014

Academic Editor: Xiaoming Li

Copyright (C) 2015 Ying-Fan Liu et al. This is an open access article distributed under the Creative Commons Attribution License, which permits unrestricted use, distribution, and reproduction in any medium, provided the original work is properly cited.

\begin{abstract}
This paper focuses on the synthesis of novel Ag nanoclusters (NCs) using DHLA as capping reagents in aqueous solution by a photoreduction method. Luminescence studies indicated that the DHLA-Ag NCs exhibited strong blue emission with maximum peak at $480 \mathrm{~nm}$. The maximum emission of the NCs can be greatly improved with irradiating time by around 15 -fold from $3 \mathrm{~h}$ to $67 \mathrm{~h}$. By means of mycelium growth rate, the results showed that the Ag NCs with smaller sizes had a good antimicrobial effect.
\end{abstract}

\section{Introduction}

Luminescent nanomaterials are currently attracting enthusiastic interest due to their applications in biomedical field such as cell imaging or photodynamic therapy [1-3], solar cells [4], lasers [5], lighting, and display technologies [6]. For bioimaging applications, luminescent semiconductor nanocrystals (quantum dots) have several advantages over the conventional organic fluorophores [7-10]. One issue with the use of small molecule fluorophores is a lack of photostability under prolonged excitation. Quantum dots also have excellent photostability, but there are potential cytotoxicity issues due to containing highly toxic metals such as cadmium $[11,12]$. Therefore, there always is a challenge to explore alternate luminescent materials.

Silver nanodots are a new class of fluorophores with photophysical properties approaching those of semiconductor quantum dots. Silver nanodots also were named as silver nanoclusters, silver clusters, or silver quantum dots, consisting of several to roughly hundred atoms, possess sizes comparable to the Fermi wavelength of electrons, and exhibit molecule-like properties, including discrete electronic transitions and strong fluorescence. Extensive efforts have been devoted to the facile preparation of highly fluorescent, water-soluble metallic nanoclusters [13-16]. Zhang et al. utilized photoreduction to synthesize Ag clusters. A mixture of silver ions and poly(N-isopropylacrylamide-acrylic acid2-hydroxy acrylate) microgel was irradiated with $365 \mathrm{~nm}$ light. As the irradiation continued, the solution became light pink, then purple, and dark red in the end [17]. Similar approach was reported with multiarm polymer [18]. Instead of UV light, visible light was applied to photoactivate a mixture of silver ions and poly(methacrylic acid) (PMAA) [19]. An increase in the silver/methacrylic acid (Ag/MAA) molar ratio resulted in red shifts of the absorption peaks and the corresponding emission peaks. A typical example is Ag clusters which exhibited a photoluminescence emission peak at $610 \mathrm{~nm}$ with excitation peaks at $400 \mathrm{~nm}$ and $450 \mathrm{~nm}$. Such stabilization might be ascribed to the strong interaction between carboxylic acid and silver ions. DNA or RNA exhibit strong affinity for silver ions; therefore, DNA or RNA molecules have been widely utilized to template 
the formation of Ag nanoparticles [20-24]. Thiol is one of the common chelating groups for synthesizing silver clusters. However, weakly luminescent $\mathrm{Ag}$ species were reported using ether 2,3-dimercaptosuccinic acid and mercaptosuccinic acid $[25,26]$ ordihydrolipoic acid (DHLA) [27-29]. In these data, the nanoparticles were usually synthesized by sodium borohydride reduction reaction. There is an urgent need to design luminescent materials with high PL QY, good stability, and low cytotoxicity. DHLA as the capping reagents has been used to synthesize the $\mathrm{CdTe}, \mathrm{HgTe}$, and $\mathrm{Ag}_{2} \mathrm{~S}$ QDs due to the fact that the bidentate DHLA can simultaneously attach to two surface sites on the QDs resulting in more stable interaction of stabilizer reagents and NCs [30-32]. Recently, Zhang et al. reported a stepwise method to prepare stable green-emitting Ag NCs. For their method, parent Ag NPs were firstly prepared using a chemical reduction method in the presence of gelatin; then, dihydrolipoic acid (DHLA) was chosen as the etching ligand [33].

Here, we present a new strong UV photochemical reduction synthesis of water-soluble luminescent Ag NCs using DHLA as the capping reagents to stabilize the Ag NCs in the solution. In the present work, we found that luminescence of DHLA-capped Ag NCs could be greatly improved by around 15 -fold from 3 to $67 \mathrm{~h}$. Also, by means of mycelium growth rate [34], antibacterial ability of the Ag NCs was tested.

\section{Experimental Section}

2.1. Chemicals. Lipoic acid (TA, 99\%) and $\mathrm{NaBH}_{4}$ (96\%) were obtained from Sigma, Inc. $\mathrm{AgNO}_{3}$ was obtained from Shanghai Chemical Reagents Company. High purity deionized water $(>18.3 \mathrm{M} \Omega / \mathrm{cm})$ was produced by Millipore A10 Milli-Q.

2.2. Preparation of Dihydrolipoic Acid (DHLA). DHLA was prepared by treating TA with $\mathrm{NaBH}_{4}$ using a method described in a previous report [27]. TA $(5.225 \mathrm{~g}, 25 \mathrm{mmol})$ was dissolved in deionized water $(200 \mathrm{~mL})$ and then $\mathrm{NaBH}_{4}$ $(1.91 \mathrm{~g}, 50 \mathrm{mmol}$ ) was slowly added to the stirred solution as a reductant. The solution was stirred at room temperature for $2 \mathrm{~h}$ and then heated to $100^{\circ} \mathrm{C}$ until no more gas $\left(\mathrm{H}_{2}\right)$ was generated. The final concentration of the DHLA aqueous solution was $0.125 \mathrm{M}$.

2.3. Synthesis of Ag Nanoclusters. Water-soluble fluorescent $\mathrm{Ag}$ nanoclusters were prepared as follows: a solution of $\mathrm{AgNO}_{3}$ in water $(85 \mathrm{mg}, 0.5 \mathrm{mmol})$ was added to the DHLA solution $(0.125 \mathrm{M}, 200 \mathrm{~mL})$ under room-temperature conditions with stirring. Silver was reduced to the zero-valent state by strong UV irradiation at $\lambda=365 \mathrm{~nm}$ (UV intensity of $400 \mathrm{~W}$ ). Aliquots of the reaction solution were removed at regular intervals for UV absorption and luminescence experiments. Samples were precipitated by acetone and dried in a vacuum oven for XPS characterization. Finally, the DHLA-Ag precipitate was dried and collected as a brown yellow powder. TEM sample was prepared by dropping the aqueous Ag nanoclusters solution onto carbon-coated copper grids and the excessive solvent was evaporated.
2.4. Assay for Antimicrobial Activity of Ag NCs against Wheat Phytoalexin. The antimicrobial activity of Ag-DHLA complex, $\mathrm{Ag}(200 \mathrm{~nm})$, and $\mathrm{Ag}(2 \mathrm{~nm}) \mathrm{NCs}$ was investigated against wheat phytoalexin. The concentration of Ag-DHLA complex, $\mathrm{Ag}(200 \mathrm{~nm})$, and $\mathrm{Ag}(2 \mathrm{~nm}) \mathrm{NCs}$ was the same as $62.5 \mathrm{uM}$. As a positive control of growth, microorganisms containing only water were used. Bacteria colony with a disk shape and diameter of $40 \mathrm{~mm}$ was reverse placed on the center of the agar plates, added into antimicrobial reagents, respectively, and then cultured in the incubator at $20^{\circ} \mathrm{C}$. The antibacterial inhibition rate of the Ag NCs was calculated from the diameter of bacterial colony when its growth diameter was $2 / 3$ of the diameter of diffusion disk. The inhibition rate $=\left(D_{1}-D_{2}\right) /\left(D_{1}-0.4\right), D_{1}$ being the diameter of control bacteria colony and $D_{2}$ being the diameter of test bacteria colony.

2.5. Characterization. UV-vis absorption and luminescence spectra were measured at room temperature with a Shimadzu UV-3100 spectrophotometer and a Hitachi 7000 fluorescence spectrometer, respectively. Luminescence spectra were taken at the excitation wavelength $\lambda_{\mathrm{ex}}=390 \mathrm{~nm}$. Time-resolved luminescence measurements were carried out on a Fluorolog3 spectrofluorometer with $390 \mathrm{~nm}$ LED lamp. Ludox was applied for PL lifetime measurement in order to eliminate the influence of light scattering (i.e., excitation and emission). Powder XRD measurements were taken on a Philips X'Pert PRO X-ray diffractometer. Transmission electron microscopy (TEM) was performed on a Philips FEI Tecnai G2 F20 S-Twin.

\section{Results and Discussion}

3.1. The Synthesis and Optical Properties of Ag NCs. Our previous research shows that luminescent pen-stabilized Ag NCs can be prepared by photoreduction method [35], but the luminescence intensity of the system is gradually decreased after irradiating for several ten min. In this study, we selected DHLA molecules as capping reagents to synthesize Ag NCs in the aqueous phase. Scheme 1 gives the synthetic route of DHLA and Ag NCs.

To produce Ag NCs, a freshly prepared aqueous solution of $2 \mathrm{mM}$ silver nitrate was added to the solution of DHLA in a molar ratio $\left[\mathrm{Ag}^{+}\right] /[\mathrm{DHLA}]$ of $50: 1$. The system was mixed and subjected to strong UV irradiation at $\lambda=365 \mathrm{~nm}$ (UV intensity of $400 \mathrm{~W}$ ) for various time intervals. The system was mixed for half an hour. Subsequently, photoreduction was carried out under UV irradiation at $\lambda=365 \mathrm{~nm}$ for various time intervals. During a total irradiation time of $67 \mathrm{~h}$, the color of the solution gradually changed from colorless to yellow. Figure 1(a) shows absorption spectra of the solution of DHLA with $\mathrm{Ag}^{+}$ions after UV irradiation for different periods of time. When the irradiation time was increased from 3 to $67 \mathrm{~h}$, the absorption band-edge slightly red shifted and the intensity of the absorbance was gradually increased, which indicated that size of the Ag NCs became correspondingly bigger and the concentration of Ag NCs was gradually increased upon prolonged UV irradiation. We noticed that, after an irradiation time of $3 \mathrm{~h}$, the reaction mixture of 


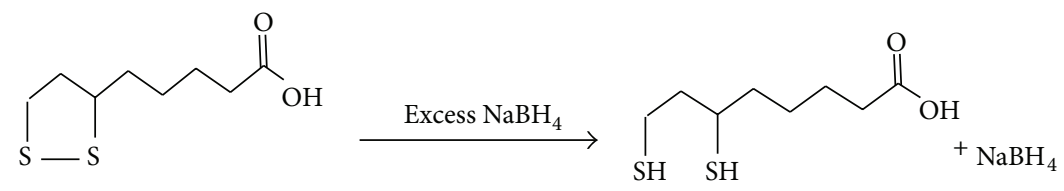

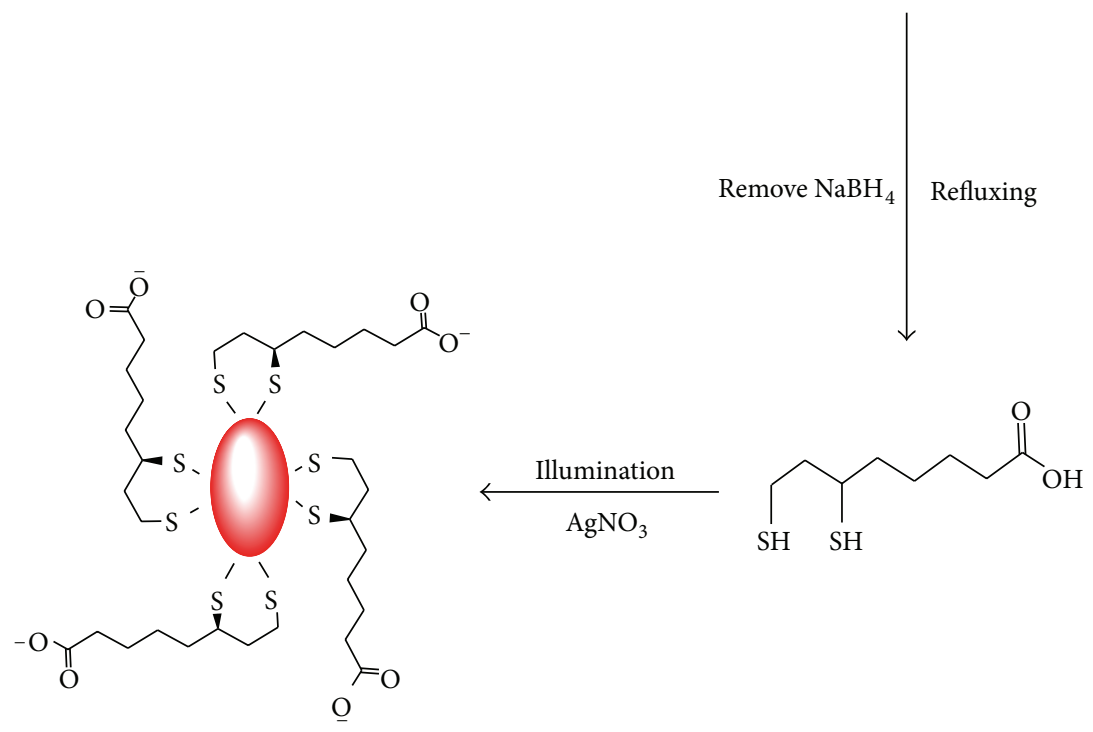

SCHEme 1: Synthesis of DHLA and Ag NCs.

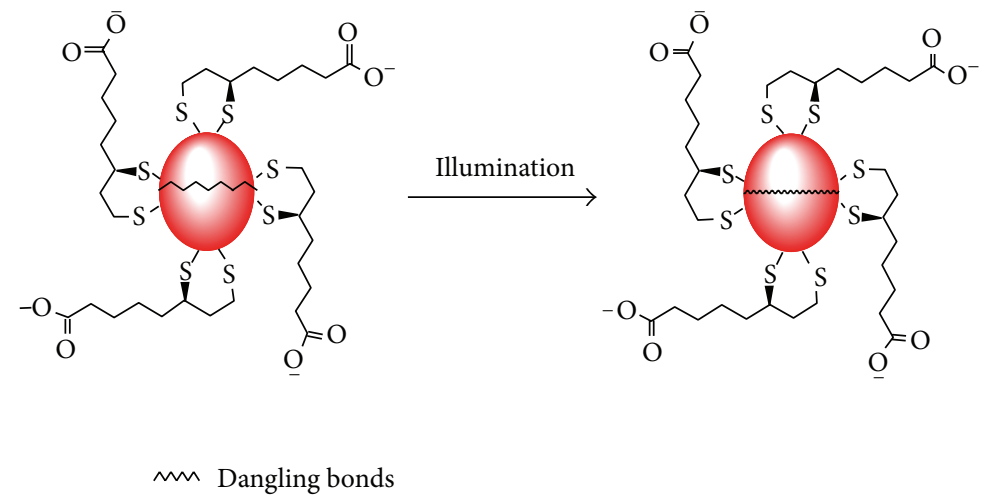

Scheme 2: Illustration of the change of surface dangling bonds on the Ag NCs.

the DHLA and $\mathrm{Ag}^{+}$ions became luminescence (Figure 1(b)). Irradiation between 3 and $67 \mathrm{~h}$ led to an emission peak centered at about $480 \mathrm{~nm}$ and spanning the wavelength range $408-630 \mathrm{~nm}$. For irradiating times of 3, 12, 25, 33, 42, 63, and $67 \mathrm{~h}, \mathrm{Ag}$ NCs are obtained with maximum blue luminescent emission at $470,472,476,477,479,482$, and $485 \mathrm{~nm}$, respectively. A strong increase in intensity was observed with increasing irradiating time, eventually resulting in a 15 -fold increase compared to the original emission. When irradiated for $67 \mathrm{~h}$, the intensity reaches a plateau. By further irradiation, the system started to precipitate. The lifetime of the Ag NCs was also measured. Figure S1 (see Supplementary Material available online at http://dx.doi.org/10.1155/2015/792095) shows the time-resolved luminescence decay curves of the Ag NCs, which can be satisfactorily fitted into triexponential function. The decay lifetime of the NCs with blue emission is $\tau_{1}=3.65 \mathrm{~ns}(52 \%), \tau_{2}=0.56 \mathrm{~ns}(31 \%)$, and $\tau_{3}=12.9 \mathrm{~ns} \mathrm{(17 \% )}$ and has a 9.4 ns average excited state lifetime. The blue emitter $\mathrm{Ex}_{350} / \mathrm{Em}_{440}$ usually exhibits a very short lifetime (0.01 ns) $[36,37]$, whereas $9.4 \mathrm{~ns}\left(\mathrm{Ex}_{390} / \mathrm{Em}_{480}\right)$ is the longest reported lifetime of such thiol-stabilized Ag NCs.

As shown in Figure 1(b), the intensity is simply enhanced as illumination is prolonged. The fact that illumination can result in increase of the luminescence of $\mathrm{Ag}$ nanocrystals has little been reported. Scheme 2 gives illustration of the change of surface dangling bonds on the Ag NCs. Due 


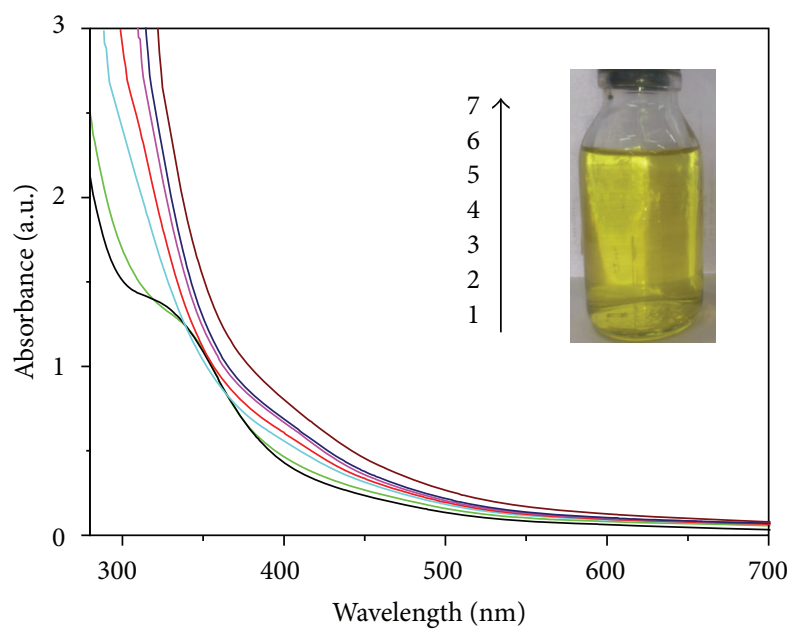

(a)

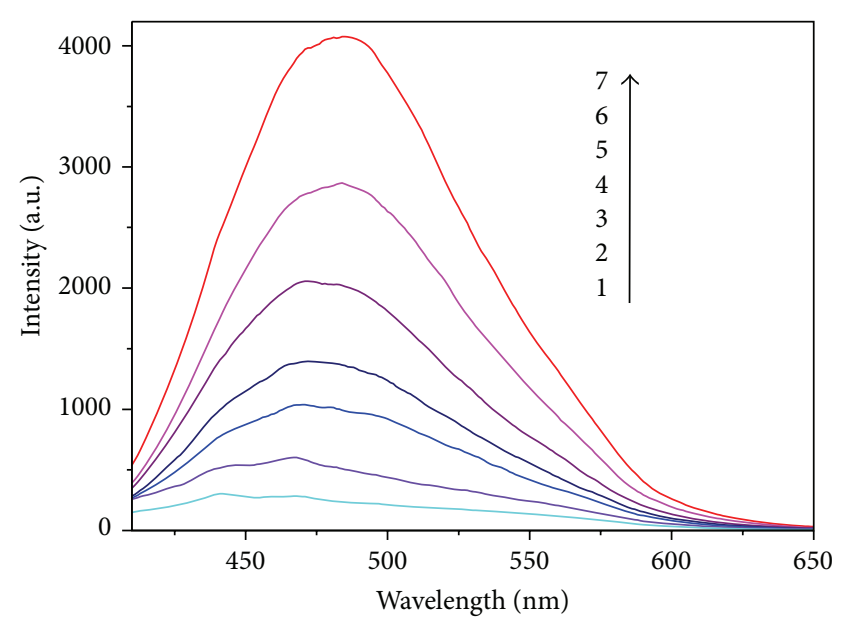

(b)

Figure 1: UV-vis (a) and luminescence spectra (b) of the Ag NCs after different periods of UV irradiation: (1) 3, (2) 12, (3) 25, (4) 33, (5) 42, (6) 63, and (8) $67 \mathrm{~h}$. The inset shows the images of Ag NCs illuminated under room natural light. The excitation wavelength was set as $390 \mathrm{~nm}$.

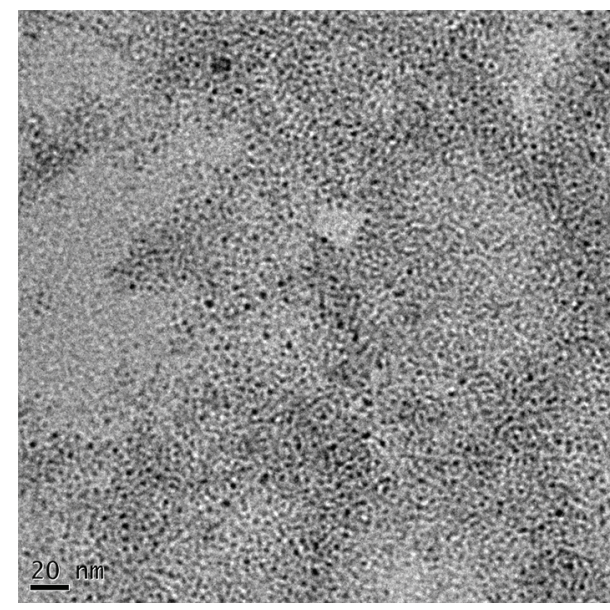

(a)

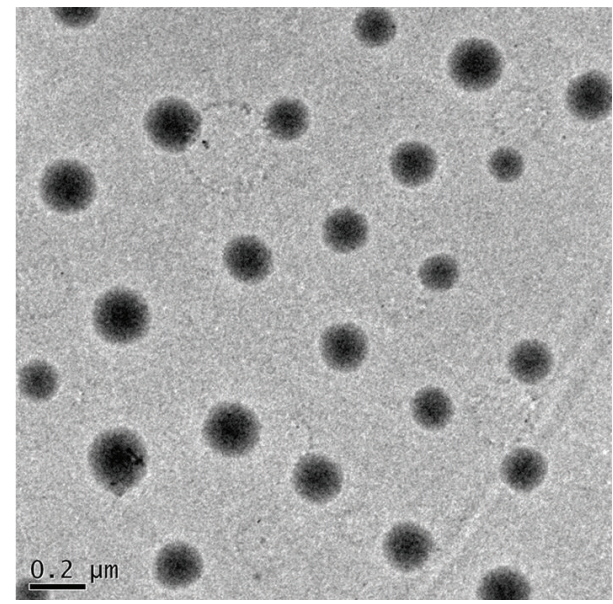

(b)

Figure 2: Typical TEM images of DHLA-capped Ag NCs obtained after irradiating for $12 \mathrm{~h}$ (a) and $63 \mathrm{~h}$ (b).

to the large surface/volume ratio, nanoclusters have lots of surface dangling bonds which become reactive upon illumination. Therefore, illumination-assisting enhancement effects were probably explained by the rearrangement of NC surface atoms and thus the decrease of dangling bonds.

It was interesting that the photoluminescence $(480 \mathrm{~nm})$ of DHLA-stabilized Ag NCs could also be obtained at the excitation wavelength $\lambda_{\mathrm{ex}}=780 \mathrm{~nm}$, which seemed to be "upconversion" phenomenon and agreed with the relevant document [38]. However, when a long pass filter, for example, $520 \mathrm{~nm}$, in the excitation part of fluorimeter was put, the photoluminescence of the NCs could not be observed. Therefore, the "upconversion" is actually due to $390 \mathrm{~nm}$ light that passes through fluorimeter (half of $780 \mathrm{~nm}$ ).

3.2. TEM, XRD, XPS, and EDX Characterization. Typical TEM images for $\mathrm{Ag} \mathrm{NCs}$ are shown in Figure 2. These images show that the Ag NCs possess a good dispersed crystalline structure and have the average diameters of about $2 \mathrm{~nm}$ after irradiating for $12 \mathrm{~h}$. Further irradiating for $63 \mathrm{~h}$, larger sized NCs formed and the average diameter of the NCs is about $200 \mathrm{~nm}$. Although the diameter of the NCs increased 100-fold, the NCs still possess a good dispersed crystalline structure and the luminescence of these NCs is greatly improved.

Powder X-ray diffractions (XRD) were carried out on the as-formed product. The XRD of the Ag NCs powder sample (Figure 3) exhibits a broad and intense (121) peak of silver at $2 \theta=\sim 35^{\circ}$, which agreed with previous result [35]. X-ray photoelectron spectroscopy was measured for the surface analysis of the washed DHLA-capped Ag NCs. A full survey scan and Ag and S photoelectron spectra of the Ag NCs are displayed in Figure 4. Besides the Ag levels, these spectra are dominated by the $\mathrm{Cls}$ and Ols signals stemming from 


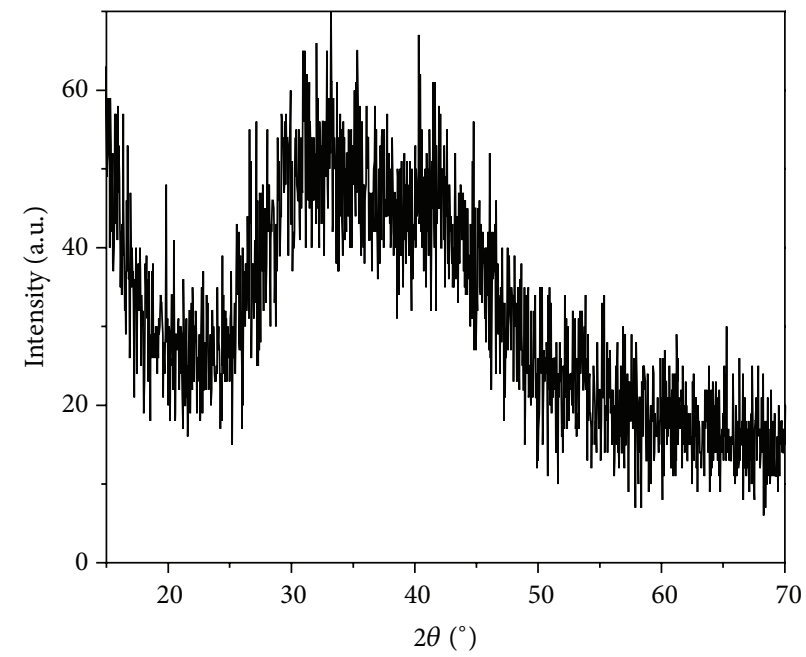

Figure 3: XRD pattern of Ag NCs.

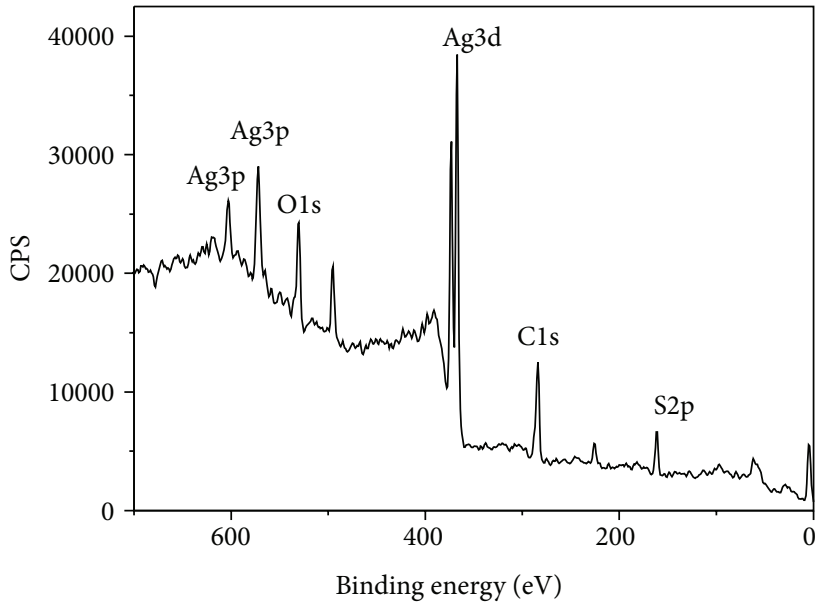

(a)

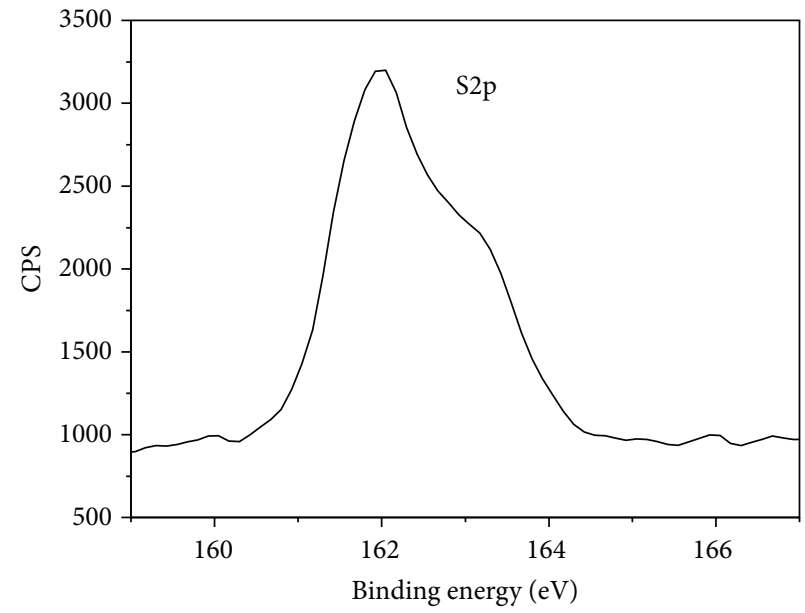

(c)

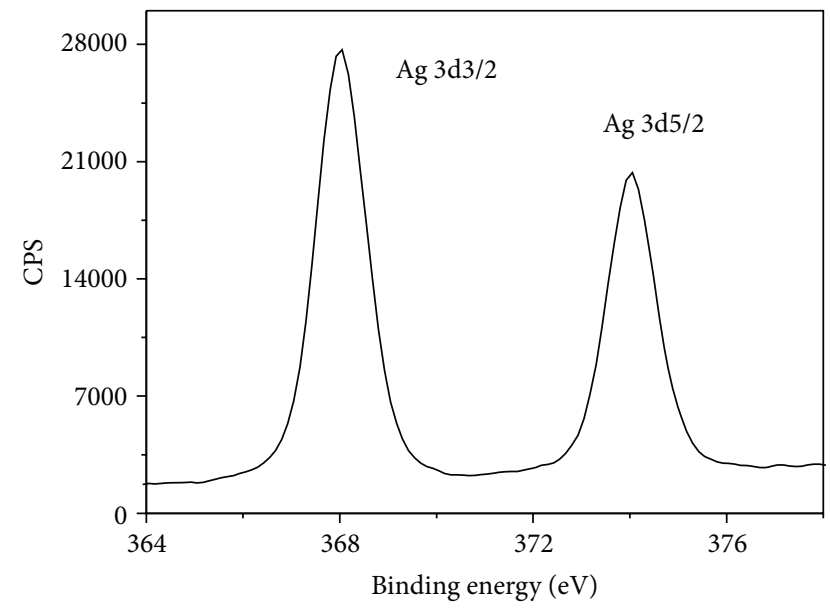

(b)

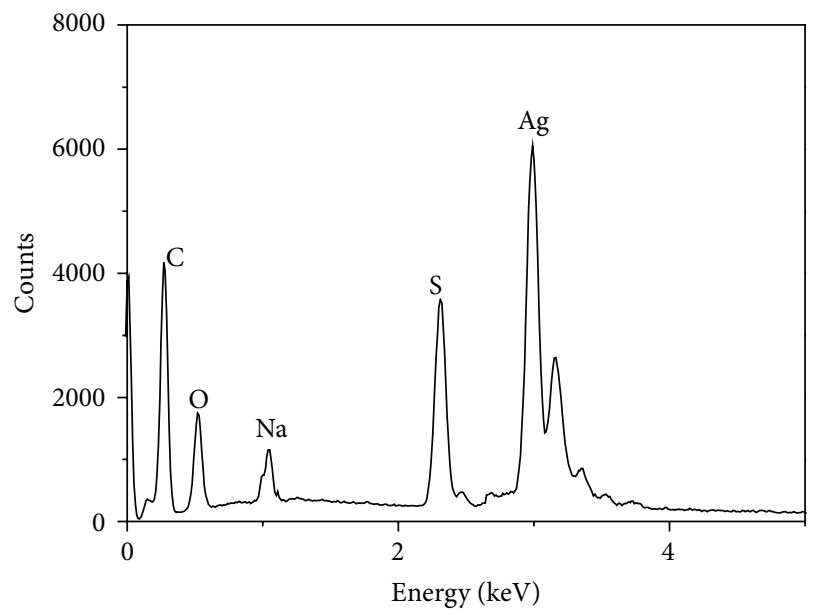

(d)

Figure 4: The XPS spectra of (a) the whole survey, (b) Ag3d, and (c) S 2p of the as-prepared Ag NCs. (d) Typical EDX spectra of DHLA-capped Ag NCs. 


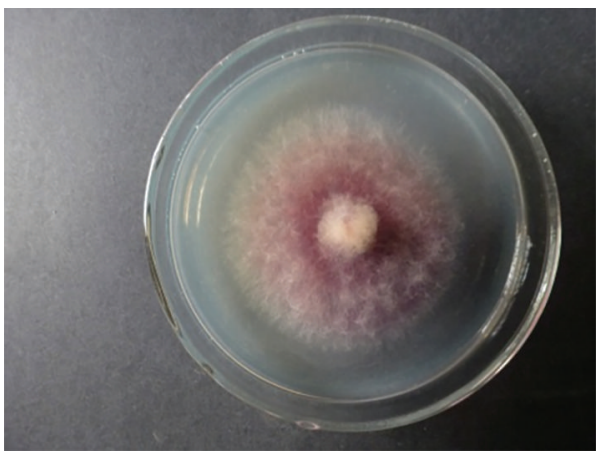

(a)

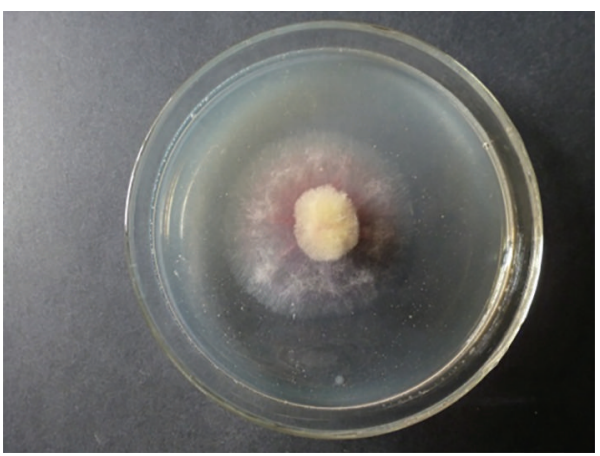

(c)

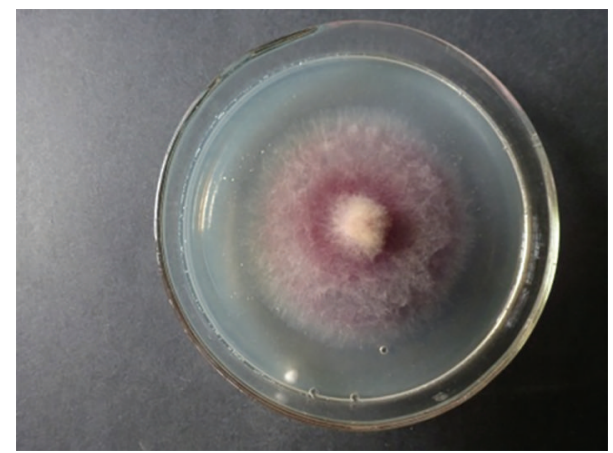

(b)

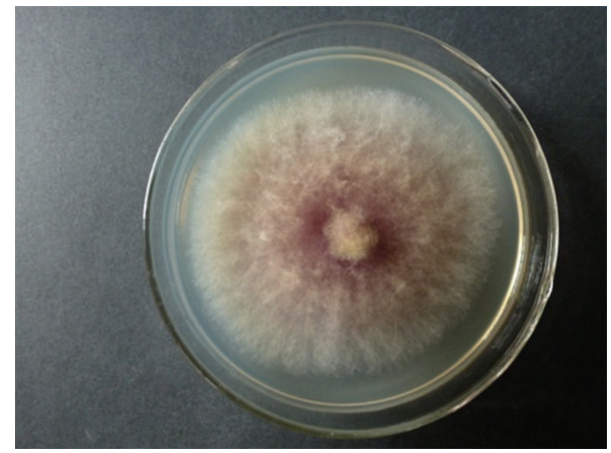

(d)

FIgure 5: Antibacterial ability of Ag NCs. Photographs were taken after incubation for $5 \mathrm{~d}$ at $20^{\circ} \mathrm{C}$. (a), (b), and (c) represent Ag-DHLA complex, $2 \mathrm{~nm} \mathrm{Ag} \mathrm{NCs,} \mathrm{and} 200 \mathrm{~nm}$ Ag NCs, respectively; (d) represents water (control). The inhibition rates of (a), (b), and (c) against wheat phytoalexin were $15.47 \%, 25.46 \%$, and $49.64 \%$, respectively. The concentration of Ag-DHLA complex was $62.5 \mu \mathrm{M}$.

the capping agent. XPS spectra in Figure 4 show that there exist Ag3d and S2p. The two peaks in Figure 4(b) of $368 \mathrm{eV}$ and $374 \mathrm{eV}$ can be assigned to the binding energy of $\mathrm{Ag}$ $3 \mathrm{~d} 5 / 2$ and $\mathrm{Ag} 3 \mathrm{~d} 3 / 2$, respectively, which is characteristic of $\mathrm{Ag}$ product [39]. The peak at $161.9 \mathrm{eV}$ belongs to S2p1/2 in a stabilizer DHLA. X-ray photoelectron spectroscopy (XPS) provides evidence for the formation of Ag NCs.

Further, we carried out energy dispersive X-ray spectroscopy (EDX) measurements for DHLA-capped Ag NCs. The EDX spectrum shows the existence of $\mathrm{Ag}$ and $\mathrm{S}$ in the $\mathrm{Ag}$ samples (Figure 4(d)). The silver sulfur and peak peaks are at $2.99 \mathrm{keV}$ and $2.3 \mathrm{keV}$, respectively, the latter mainly from the stabilizer DHLA.

3.3. Assay for Antimicrobial Activity of Ag NCs. Recently silver nanoparticles became a fresh member of antimicrobial $\mathrm{Ag}$ family due to their higher specific surface area and high fraction of surface atoms compared to bulk Ag [40, 41]. By means of mycelium growth rate, the results showed that, at the same conditions, the inhibition rates of $\mathrm{Ag}^{+}, \mathrm{Ag}$ $(200 \mathrm{~nm})$, and $\mathrm{Ag}(2 \mathrm{~nm})$ against wheat phytoalexin were $15.47 \%, 25.46 \%$, and $49.64 \%$, respectively (Figure 5). Therefore, the Ag NCs with smaller sizes had a good antimicrobial effect, which might be caused by their larger surface area and higher surface energy. Ag NCs break permeability of outer membrane, inhibit respiration and growth of cells, and destroy the structure of membrane, resulting in cell decomposition and death eventually.

\section{Summary}

In summary, to the best of our knowledge, this is the first report of a synthesis of DHLA-capped Ag NCs by photoreduction method. The prepared DHLA-stabilized Ag NCs exhibited strong PL emission with maximum peak at $480 \mathrm{~nm}$. Because luminescence of these NCs can be greatly improved, they may be found in vast applications, not only in chemistry and biology such as biolabeling and imaging but also in forensic science. The test of antimicrobial activity showed that the Ag NCs with smaller sizes had a good antimicrobial effect.

\section{Conflict of Interests}

The authors declare that there is no conflict of interests regarding the publication of this paper.

\section{Acknowledgments}

This work was financially supported by the Natural Science Foundation of China (nos. 21171150 and 21271159) and Henan Province Science and Technology Programs (no. 112102210002).

\section{References}

[1] X. Michalet, F. F. Pinaud, L. A. Bentolila et al., "Quantum dots for live cells, in vivo imaging, and diagnostics," Science, vol. 307, no. 5709 , pp. 538-544, 2005. 
[2] X. M. Li, L. Wang, Y. B. Fan, Q. L. Feng, F. Z. Cui, and F. Watari, "Nanostructured scaffolds for bone tissue engineering," Journal of Biomedical Materials Research Part A, vol. 101, pp. 2424-2435, 2013.

[3] X. Li, H. Liu, X. Niu et al., "The use of carbon nanotubes to induce osteogenic differentiation of human adipose-derived MSCs in vitro and ectopic bone formation in vivo," Biomaterials, vol. 33, no. 19, pp. 4818-4827, 2012.

[4] H. Q. Wang, M. Batentschuk, A. Osvet, L. Pinna, and C. J. Brabec, "Rare-earth ion doped up-conversion materials for photovoltaic applications," Advanced Materials, vol. 23, no. 2223, pp. 2675-2680, 2011.

[5] T. Danger, J. Koetke, R. Brede, E. Heumann, G. Huber, and B. H. T. Chai, "Spectroscopy and green upconversion laser emission of $\mathrm{Er}^{3+}$-doped crystals at room temperature," Journal of Applied Physics, vol. 76, no. 3, pp. 1413-1422, 1994.

[6] A. Rapaport, J. Milliez, M. Bass, A. Cassanho, and H. Jenssen, "Review of the properties of up-conversion phosphors for new emissive displays," Journal of Display Technology, vol. 2, no. 1, pp. 68-78, 2006.

[7] F. Wang and X. G. Liu, "Recent advances in the chemistry of lanthanide-doped upconversion nanocrystals," Chemical Society Reviews, vol. 38, no. 4, pp. 976-989, 2009.

[8] W.-H. Zhang, C.-X. Sui, X. Wang, G.-J. Yin, Y.-F. Liu, and D. Zhang, "Characterization of $\mathrm{Cr}(\mathrm{V})$-induced genotoxicity using CdTe nanocrystals as fluorescent probes," Analyst, 2014.

[9] C.-X. Sui, Y.-F. Liu, W.-H. Zhang, P.-A. Li, and D. Zhang, "CdTeCdSe nanocrystals capped with dimethylaminoethanethiol as ultrasensitive fluorescent probes for chromium(VI)," Microchimica Acta, vol. 181, no. 3-4, pp. 347-353, 2014.

[10] Y.-F. Liu, L. Wang, W.-Z. Shi, Y.-H. Zhang, and S.-M. Fang, "Synthesis and characterization of chiral Ag2S and Ag2S-Zn nanocrystals," RSC Advances, vol. 4, no. 95, pp. 53142-53148, 2014.

[11] Z. Deng, Y. Zhang, J. Yue, F. Tang, and Q. Wei, "Green and orange CdTe quantum dots as effective $\mathrm{pH}$-sensitive fluorescent probes for dual simultaneous and independent detection of viruses," Journal of Physical Chemistry B, vol. 111, no. 41, pp. 12024-12031, 2007.

[12] N. Lewinski, V. Colvin, and R. Drezek, "Cytotoxicity of nanoparticles," Small, vol. 4, no. 1, pp. 26-49, 2008.

[13] G. Maduraiveeran and R. Ramaraj, "Potential sensing platform of silver nanoparticles embedded in functionalized silicate shell for nitroaromatic compounds," Analytical Chemistry, vol. 81, no. 18, pp. 7552-7560, 2009.

[14] H. Xu and K. S. Suslick, "Water-soluble fluorescent silver nanoclusters," Advanced Materials, vol. 22, no. 10, pp. 1078-1082, 2010.

[15] L. Shang, S. Dong, and G. U. Nienhaus, "Ultra-small fluorescent metal nanoclusters: synthesis and biological applications," Nano Today, vol. 6, no. 4, pp. 401-418, 2011.

[16] T. Zhou, M. Rong, Z. Cai, C. Yang, and X. Chen, "Sonochemical synthesis of highly fluorescent glutathione-stabilized Ag nanoclusters and S2-sensing," Nanoscale, vol. 4, no. 14, pp. 41034106, 2012.

[17] J. Zhang, S. Xu, and E. Kumacheva, "Photogeneration of fluorescent silver nanoclusters in polymer microgels," Advanced Materials, vol. 17, no. 19, pp. 2336-2340, 2005.

[18] Z. Shen, H. W. Duan, and H. Frey, "Water-soluble fluorescent Ag nanoclusters obtained from multiarm star poly(acrylic acid) as "molecular hydrogel" templates," Advanced Materials, vol. 19, no. 3, pp. 349-352, 2007.
[19] I. Díez, M. Pusa, S. Kulmala et al., "Color tunability and electrochemiluminescence of silver nanoclusters," Angewandte Chemie, vol. 48, no. 12, pp. 2122-2125, 2009.

[20] J. T. Petty, J. Zheng, N. V. Hud, and R. M. Dickson, "DNAtemplated Ag nanocluster formation," Journal of the American Chemical Society, vol. 126, no. 16, pp. 5207-5212, 2004.

[21] L. Berti and G. A. Burley, "Nucleic acid and nucleotidemediated synthesis of inorganic nanoparticles," Nature Nanotechnology, vol. 3, no. 2, pp. 81-87, 2008.

[22] C. M. Ritchie, K. R. Johnsen, J. R. Kiser, Y. Antoku, R. M. Dickson, and J. T. Petty, "Ag nanocluster formation using a cytosine oligonucleotide template," Journal of Physical Chemistry C, vol. 111, no. 1, pp. 175-181, 2007.

[23] P. R. O’Neill, L. R. Velazquez, D. G. Dunn, E. G. Gwinn, and D. K. Fygenson, "Hairpins with poly-C loops stabilize four types of fluorescent $\mathrm{Ag}_{n}$ : DNA," The Journal of Physical Chemistry C, vol. 113, no. 11, pp. 4229-4233, 2009.

[24] Y. Wei, R. Liu, Z. Sun et al., "Luminescent silver nanoclusters anchored by oligonucleotides detect human telomerase ribonucleic acid template," Analyst, vol. 138, no. 5, pp. 1338-1341, 2013.

[25] Z. Wu, E. Lanni, W. Chen, M. E. Bier, D. Ly, and R. Jin, "High yield, large scale synthesis of thiolate-protected $\mathrm{Ag}_{7}$ clusters," Journal of the American Chemical Society, vol. 131, no. 46, pp. 16672-16674, 2009.

[26] T. U. B. Rao, B. Nataraju, and T. Pradeep, "Ag9 quantum cluster through a solid-state route," Journal of the American Chemical Society, vol. 132, no. 46, pp. 16304-16307, 2010.

[27] P. T. K. Chin, M. van der Linden, E. J. van Harten et al., "Enhanced luminescence of Ag nanoclusters via surface modification," Nanotechnology, vol. 24, no. 7, Article ID 075703, 2013.

[28] L. Shang, R. M. Dörlich, V. Trouillet, M. Bruns, and G. U. Nienhaus, "Ultrasmall fluorescent silver nanoclusters: protein adsorption and its effects on cellular responses," Nano Research, vol. 5, no. 8, pp. 531-542, 2012.

[29] B. Adhikari and A. Banerjee, "Facile synthesis of water-soluble fluorescent silver nanoclusters and HgII sensing," Chemistry of Materials, vol. 22, no. 15, pp. 4364-4371, 2010.

[30] Y.-F. Liu, B. Xie, Z.-G. Yin, S.-M. Fang, and J.-B. Zhao, "Synthesis of highly stable $\mathrm{CdTe} / \mathrm{CdS}$ quantum dots with biocompatibility," European Journal of Inorganic Chemistry, vol. 2010, no. 10, pp. 1501-1506, 2010.

[31] W. H. Zhang, J. Yang, and J. S. Yu, "Synthesis of stable near-infrared emitting $\mathrm{HgTe} / \mathrm{CdS}$ core/shell nanocrystals using dihydrolipoic acid as stabilizer," Journal of Materials Chemistry, vol. 22, no. 13, pp. 6383-6388, 2012.

[32] Y. Zhang, Y. Zhang, G. Hong et al., "Biodistribution, pharmacokinetics and toxicology of $\mathrm{Ag}_{2} \mathrm{~S}$ near-infrared quantum dots in mice," Biomaterials, vol. 34, no. 14, pp. 3639-3646, 2013.

[33] C. Zhang, X. Sun, J. Li, and Y.-N. Liu, "Synthesis of Ag nanoclusters by a $\mathrm{pH}$-dependent etching method in aqueous solution," Nanoscale, vol. 5, no. 14, pp. 6261-6264, 2013.

[34] I. Sondi and B. Salopek-Sondi, "Silver nanoparticles as antimicrobial agent: a case study on E. coli as a model for Gramnegative bacteria," Journal of Colloid and Interface Science, vol. 275, no. 1, pp. 177-182, 2004.

[35] Y.-F. Liu, G.-Q. Wang, J.-B. Zhao, L. Jiang, S.-M. Fang, and Y.-A. Sun, "Synthesis of chiral silver nanoclusters capped with small molecules," Colloids and Surfaces A, vol. 426, pp. 12-17, 2013.

[36] T. U. B. Rao and T. Pradeep, "Luminescent $\mathrm{Ag}_{7}$ and $\mathrm{Ag}_{8}$ clusters by interfacial synthesis," Angewandte Chemie, vol. 49, no. 23, pp. 3925-3929, 2010. 
[37] G. de Cremer, E. Coutiño-Gonzalez, M. B. J. Roeffaers et al., "Characterization of fluorescence in heat-treated silverexchanged zeolites," Journal of the American Chemical Society, vol. 131, no. 8, pp. 3049-3056, 2009.

[38] Q. Cui, Y. Shao, K. Ma, S. Xu, F. Wu, and G. Liu, "Upconversion emission of fluorescent silver nanoclusters and in situ selective DNA biosensing," Analyst, vol. 137, no. 10, pp. 2362-2366, 2012.

[39] S. Pan, X. Liu, and X. Wang, "Preparation of Ag2S-Graphene nanocomposite from a single source precursor and its surfaceenhanced Raman scattering and photoluminescent activity," Materials Characterization, vol. 62, no. 11, pp. 1094-1101, 2011.

[40] X. M. Wang, W. R. Gao, S. P. Xu, and W. Q. Xu, "Luminescent fibers: in situ synthesis of silver nanoclusters on silk via ultraviolet light-induced reduction and their antibacterial activity," Chemical Engineering Journal, vol. 210, pp. 585-589, 2012.

[41] T. Xu, L. Wu, Y. Yu, W. Li, and J. Zhi, "Synthesis and characterization of diamond-silver composite with anti-bacterial property," Materials Letters, vol. 114, pp. 92-95, 2014. 

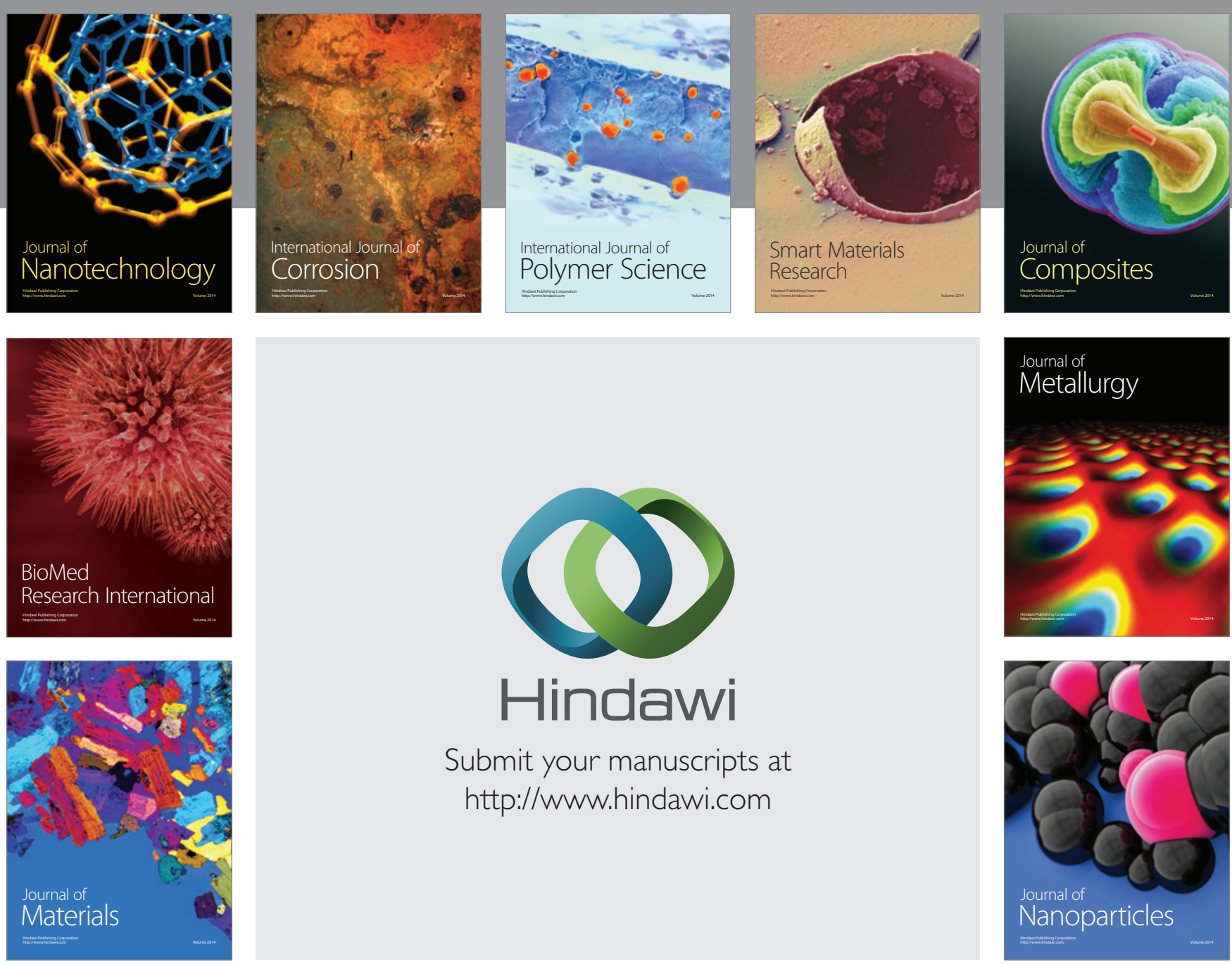

Submit your manuscripts at http://www.hindawi.com
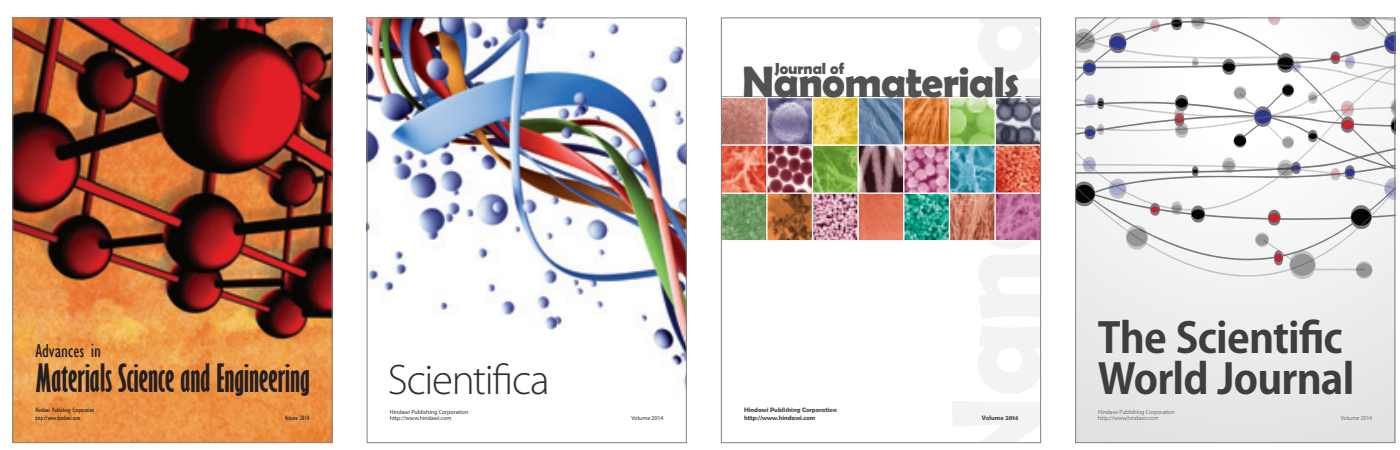

\section{The Scientific World Journal}
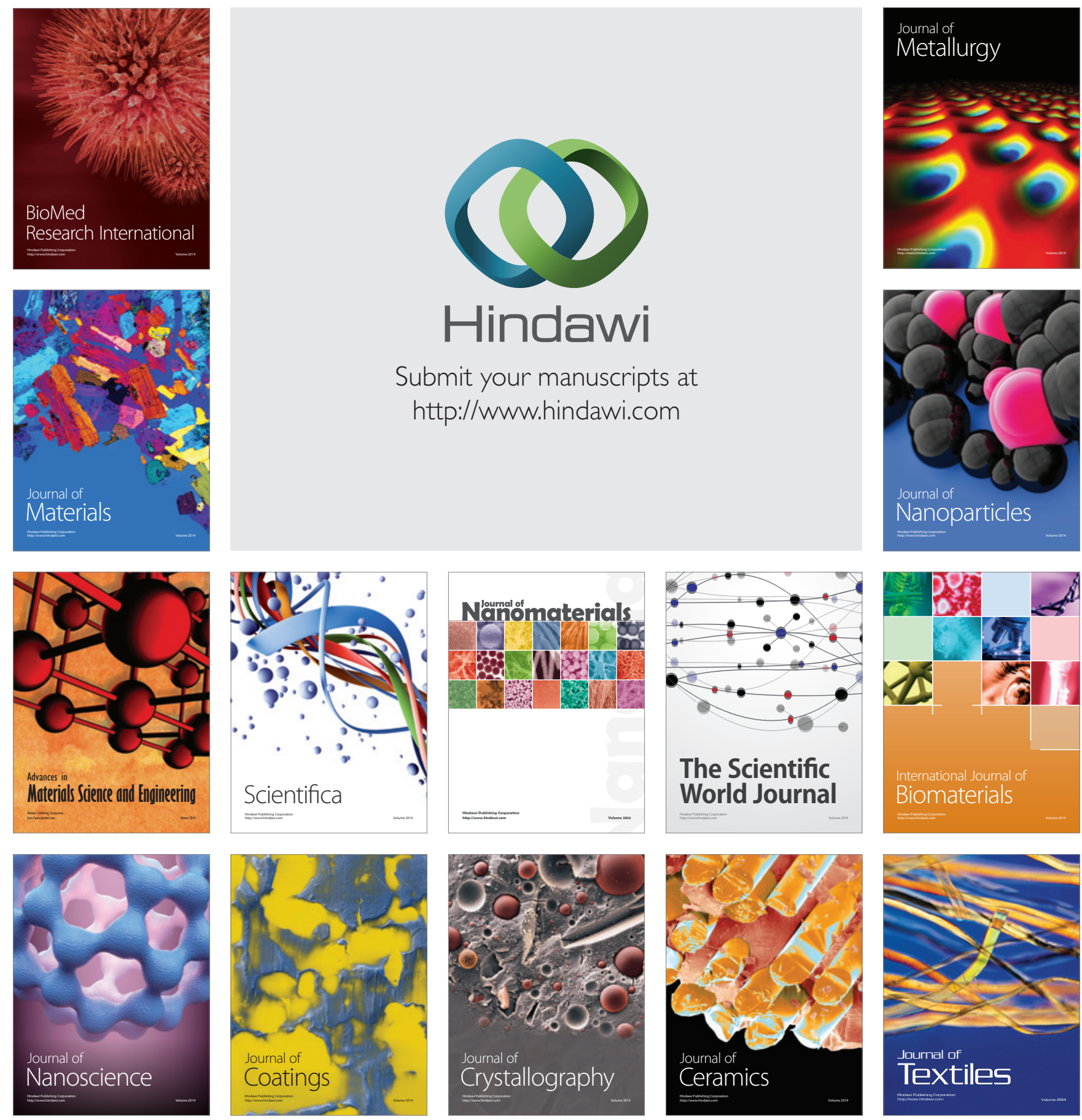